\title{
Biologia reprodutiva de duas espécies de Jatropha L. (Euphorbiaceae) em Caatinga, Nordeste do Brasil ${ }^{1}$
}

\author{
MARY JANICE SANTOS², ISABEL CRISTINA MACHADO ${ }^{3,4}$ e ARIADNA VALENTINA LOPES ${ }^{3}$
}

(recebido: 8 de abril de 2004; aceito: 10 de fevereiro de 2005)

\begin{abstract}
Reproductive biology of two species of Jatropha L. (Euphorbiaceae) in "Caatinga", northeastern Brazil). The phenology, pollination and breeding system of Jatropha mutabilis (Pohl) Baill. and J. mollissima (Pohl) Baill. were studied in the municipalities of Buíque ( $8^{\circ} 67^{\prime} \mathrm{S}$ and $37^{\circ} 01^{\prime} \mathrm{W}$ ) and Arcoverde ( $8^{\circ} 25^{\prime} \mathrm{S}$ and $37^{\circ} 02^{\prime} \mathrm{W}$ ), both in the Caatinga, Pernambuco state. Twenty individuals of each species were tagged for phenological observations, and the study of floral biology, reproductive system, as well as the frequency and behaviour of floral visitors. The species are monoecious, with diurnal dish flowers, the male ones more ephemeral $(12 \mathrm{~h}$ ) than the female ( $36 \mathrm{~h})$. The sugar concentration in the nectar of J. mutabilis and J. mollissima varied between $26 \%-32 \%$ and $20 \%-28 \%$, respectively. Volume was usually greater $(16 \mu \mathrm{L})$ in female flowers of both species. Pollen viability was high (> 97\%). Both species are self-compatible. The percentage of fruit set under natural conditions was c. $75 \%$ in J. mutabilis and of $85 \%$ in J. mollissima, indicating high reproductive success. The flowers are pollinated by bees and wasps, and also by hummingbirds in J. mutabilis and butterflies in J. mollissima. The species have flowers along the whole year, thus they are important resources for the maintenance of the local communities of animals that visit them. Also, the presence and effectiveness of these groups of pollinators are fundamental for both plant species, since they are responsible for the pollen flow among male and female flowers in these monoecious shrubs.
\end{abstract}

Key words - Caatinga, Jatropha, monoecy, pollination, reproductive phenology

RESUMO - (Biologia reprodutiva de duas espécies de Jatropha L. (Euphorbiaceae) em Caatinga, Nordeste do Brasil). A polinização, o sistema reprodutivo e a fenologia de floração e de frutificação de Jatropha mutabilis (Pohl) Baill. e J. mollissima (Pohl) Baill. foram estudados no Estado de Pernambuco, nos Municípios de Buíque ( $8^{\circ} 67^{\prime} \mathrm{S}$ e $\left.37^{\circ} 01^{\prime} \mathrm{W}\right)$ e Arcoverde $\left(8^{\circ} 25^{\prime} \mathrm{S}\right.$ e $37^{\circ} 02^{\prime}$ W), ambos em Caatinga. Foram marcados 20 indivíduos de cada espécie para registro dos dados fenológicos, aspectos da biologia floral, sistema reprodutivo, bem como freqüência e comportamento dos visitantes florais. As duas espécies são monóicas, apresentam flores do tipo disco, com antese floral diurna, havendo variação em relação à longevidade das flores nos dois sexos, sendo as flores masculinas mais efêmeras ( $12 \mathrm{~h}$ ), e as femininas mais duradouras ( $36 \mathrm{~h}$ ). Ambos os tipos florais são nectaríferos e a concentração de açúcares no néctar variou entre $26 \%$ e $32 \%$ em J. mutabilis e $20 \%$ a $28 \%$ em J. mollissima. A viabilidade do pólen foi alta (> 97\%) em ambas as espécies. As espécies são autocompatíveis, formando frutos tanto nos tratamentos de geitonogamia como nos de xenogamia. O percentual de formação de frutos em condições naturais foi ca. $75 \%$ em J. mutabilis e de $85 \%$ em J. mollissima, indicando alto sucesso reprodutivo. As flores de ambas as espécies são polinizadas por abelhas e vespas, além de beija-flores em J. mutabilis e borboletas em J. mollissima. As duas espécies permanecem floridas ao longo do ano, sendo importante fonte de recurso para a manutenção das comunidades locais de animais que visitam suas flores. Em contrapartida, a presença e eficácia destes grupos de polinizadores são fundamentais para que se estabeleça o fluxo de pólen entre as flores masculinas e femininas, uma vez que as espécies são monóicas.

Palavras-chave - Caatinga, fenologia reprodutiva, Jatropha, monoicia, polinização

\section{Introdução}

A família Euphorbiaceae, com cerca de 317 gêneros e 8.000 espécies, distribui-se principalmente nos trópicos

1. Parte da dissertação de mestrado do primeiro autor (Programa de Pós-Graduação em Biologia Vegetal da UFPE).

2. Universidade Federal de Pernambuco, Programa de PósGraduação em Biologia Vegetal.

3. Universidade Federal de Pernambuco, Departamento de Botânica, Rua Prof. Nelson Chaves s/n, 50372-970, RecifePE.

4. Autor para correspondência: imachado@ufpe.br e subtrópicos (Cronquist 1981), sendo a segunda família mais representativa da Caatinga em número de espécies, superada apenas por Leguminosae (Sampaio 1995). Possui espécies hermafroditas, monóicas e dióicas, sendo, na maioria das vezes, visitadas por vários grupos de polinizadores, o que as caracteriza como "generalistas" (Webster 1994). Há, entretanto, exemplos como as espécies de Dalechampia L. cujas flores oferecem recompensas especializadas como resinas ou perfumes, sendo polinizadas por abelhas Euglossini e Megachilidae (Armbruster \& Webster 1979, Sazima et al. 1985, Armbruster \& McCormick 1990, Armbruster \& Steiner 1992, Armbruster et al. 1992). 
O gênero Jatropha L. é constituído por 175 espécies tropicais e subtropicais (Webster 1994), monóicas, dióicas ou raramente poligâmicas (Gallindo 1985). Estudos de polinização no gênero são raros (Dehgan \& Webster 1979, Reddi \& Reddi 1983, Ormond et al. 1984, Epila-Otara 1993), fato já apontado por Dehgan \& Webster (1979) e Ormond et al. (1984). Jatropha mutabilis (Pohl) Baill. é uma espécie monóica, endêmica de Caatinga, ocorrendo desde o Piauí até a Bahia, em áreas de Caatinga hiperxerófila, sendo encontrada em terreno arenoso (Gallindo 1985). Jatropha mollissima (Pohl) Baill. também é monóica, com distribuição mais ampla, ocorrendo em todos os estados do Nordeste do Brasil, exceto no Maranhão, habitando áreas de Caatinga hipo e hiperxerófila, bem como Restingas (Gallindo 1985).

O presente trabalho aborda comparativamente a fenologia reprodutiva, a biologia floral e o sistema reprodutivo de Jatropha mutabilis e J. mollissima, ressaltando a importância das interações de espécies monóicas com seus agentes polinizadores.

\section{Material e métodos}

Locais de estudo - Os estudos de campo foram desenvolvidos em duas áreas de Caatinga. As observações em Jatropha mutabilis (Pohl) Baill. foram feitas no Parque Nacional do Catimbau ( $8^{\circ} 67^{\prime}$ S e $37^{\circ} 01^{\prime} \mathrm{W}$ ), localizado no Município de Buíque, Agreste Meridional do Estado de Pernambuco, distando $290 \mathrm{~km}$ de Recife. As precipitações pluviométricas atingem anualmente a média de $1095,9 \mathrm{~mm}$ e a temperatura média anual é de $27{ }^{\circ} \mathrm{C}$ (FIDEM 2000). As observações de J. mollissima (Pohl) Baill. foram realizadas em uma das estações de pesquisa da Empresa Pernambucana de Pesquisa Agropecuária (IPA), localizada no Município de Arcoverde ( $8^{\circ} 25^{\prime} \mathrm{S}$ e $\left.37^{\circ} 02^{\prime} \mathrm{W}\right)$, também em Pernambuco, na Região Sertão do Estado, distando $256 \mathrm{~km}$ de Recife. A precipitação média anual é de ca. $750 \mathrm{~mm}$ e a temperatura média anual de $27^{\circ} \mathrm{C}$ (FIDEM 2000).

Procedimentos - $\mathrm{O}$ trabalho de campo foi desenvolvido durante os anos de 1999 e 2000, sendo marcados 20 indivíduos de cada espécie, nos quais foram coletados dados sobre a fenologia reprodutiva, morfologia, dimensões, cor, odor, horário, duração e sequiência de antese floral, número de botões femininos e masculinos por inflorescência, localização e tipo de recompensa floral.

A fenologia, de floração e de frutificação, foi acompanhada mensalmente, entre os meses de novembro/1999 e novembro/2000, nos 20 indivíduos marcados para cada espécie. Foram utilizadas fichas de campo para registrar a presença ou ausência de botões, flores e frutos, seguindo indicações de Morellato et al. (1990) e Machado et al. (1997). A cada visita ao campo, a partir da observação dos indivíduos marcados, foram anotados o número de flores femininas e masculinas abertas, bem como o total de indivíduos floridos. O padrão de floração das espécies foi determinado a partir da classificação de Newstrom et al. (1994).

A viabilidade polínica foi verificada utilizando-se a técnica de coloração do citoplasma com TTC $(2,3,5$ trifeniltetrazolium clorídrico), segundo Dafni (1992). Em dois indivíduos de $J$. mutabilis, nos quais foram registradas algumas flores hermafroditas, a viabilidade do pólen dessas flores, além das masculinas, também foi verificada utilizandose a mesma técnica citada anteriormente.

A contagem do número de grãos de pólen por antera foi realizada sob microscópio fotônico, sendo utilizados 10 botões, de cada espécie, em fase de pré-antese, coletados de indivíduos diferentes. De cada botão foram retiradas duas anteras e a contagem foi realizada para cada uma delas, separadamente.

A concentração de açúcares e o volume do néctar foram medidos, respectivamente, com auxílio de refratômetro de bolso (Atago ${ }^{\circledR}$ 0\%-32\% e 28\%-62\%) e de microseringas (Microliter® 10 e $25 \mu \mathrm{L}$ ) em flores previamente ensacadas. Vinte flores femininas e 20 masculinas, de cada espécie, foram ensacadas no dia anterior à antese, sendo as medidas efetuadas no campo, durante a antese.

Para análise do sistema reprodutivo foram realizados tratamentos para verificar a ocorrência de apomixia, polinização pelo vento e autocompatibilidade, além da formação de frutos em condições naturais, segundo metodologia adaptada de Radford et al. (1974). Para os testes de apomixia e polinização pelo vento, botões femininos foram cobertos, respectivamente, com sacos de papel semipermeável e sacos de tule, no dia anterior à antese, e permaneceram ensacados até o murchamento das flores. Para verificar a ocorrência de geitonogamia, botões também ensacados com papel semi-permeável foram polinizados com pólen proveniente de flores masculinas do mesmo indivíduo. Nos testes de xenogamia, a polinização foi feita com pólen de outro indivíduo. As flores, polinizadas manualmente em todos os testes, foram novamente ensacadas e etiquetadas, sendo os sacos retirados apenas após o seu murchamento.

Para se observar a frutificação natural em J. mutabilis, durante os períodos nos quais as classes de polinizadores foram diferentes ou se sobrepuseram, 20 flores femininas foram marcadas em intervalos de quatro meses. Em J. mollissima esse tratamento não foi realizado por não ter sido observada sazonalidade nas classes de visitantes.

Para as duas espécies foram realizadas observações no campo sobre o tipo, frequiência, horário e comportamento dos animais visitantes às flores, além do recurso floral procurado e o resultado das visitas (polinização ou pilhagem). De acordo com a eficiência em contatar as partes reprodutivas das flores, em decorrência do tamanho do corpo e/ou do comportamento de visita, os visitantes polinizadores foram classificados como efetivos, quando possuíam tamanho e comportamento adequados à polinização, ou ocasionais, 
quando, devido ao pequeno tamanho ou ao comportamento inadequado, nem sempre realizavam a polinização. As visitas foram documentadas com máquina fotográfica. Alguns exemplares dos insetos visitantes foram coletados com rede entomológica e mantidos à seco, sendo identificados e depositados na coleção do Laboratório de Biologia Floral e Reprodutiva do Departamento de Botânica da UPPE. Foram analisados os atributos morfológicos dos animais, bem como os locais de deposição de pólen.

Material botânico contendo ramos vegetativos e reprodutivos das duas espécies foi coletado e depositado no Herbário UFP do Departamento de Botânica da UFPE.

\section{Resultados}

Hábito e fenologia reprodutiva - Ambas as espécies estudadas de Jatropha são arbustivas e perenifólias, sendo J. mutabilis mais ramificada que J. mollissima.
A floração das duas espécies estendeu-se durante todo o ano, sendo a produção de flores masculinas superior àquela de flores femininas durante todos os meses. As duas espécies apresentaram fenologia reprodutiva relativamente semelhante, registrando-se, em ambas, o maior percentual de indivíduos floridos (90\% a 100\%) entre os meses de outubro e novembro, sendo agosto e setembro os meses nos quais se encontrou o menor número de indivíduos com flores (figura 1A, B). Nesse mesmo período, porém, foi registrada a maior produção, em termos percentuais, de flores femininas nas duas espécies. Flores femininas foram ausentes em junho em J. mutabilis (figura 1A) e em julho em J. mollissima (figura 1B). A formação de frutos, nas duas espécies, ocorreu também durante todo o ano, entretanto, no período de setembro a novembro foi registrada a menor produção, ocasião em que apenas $20 \%$ dos indivíduos
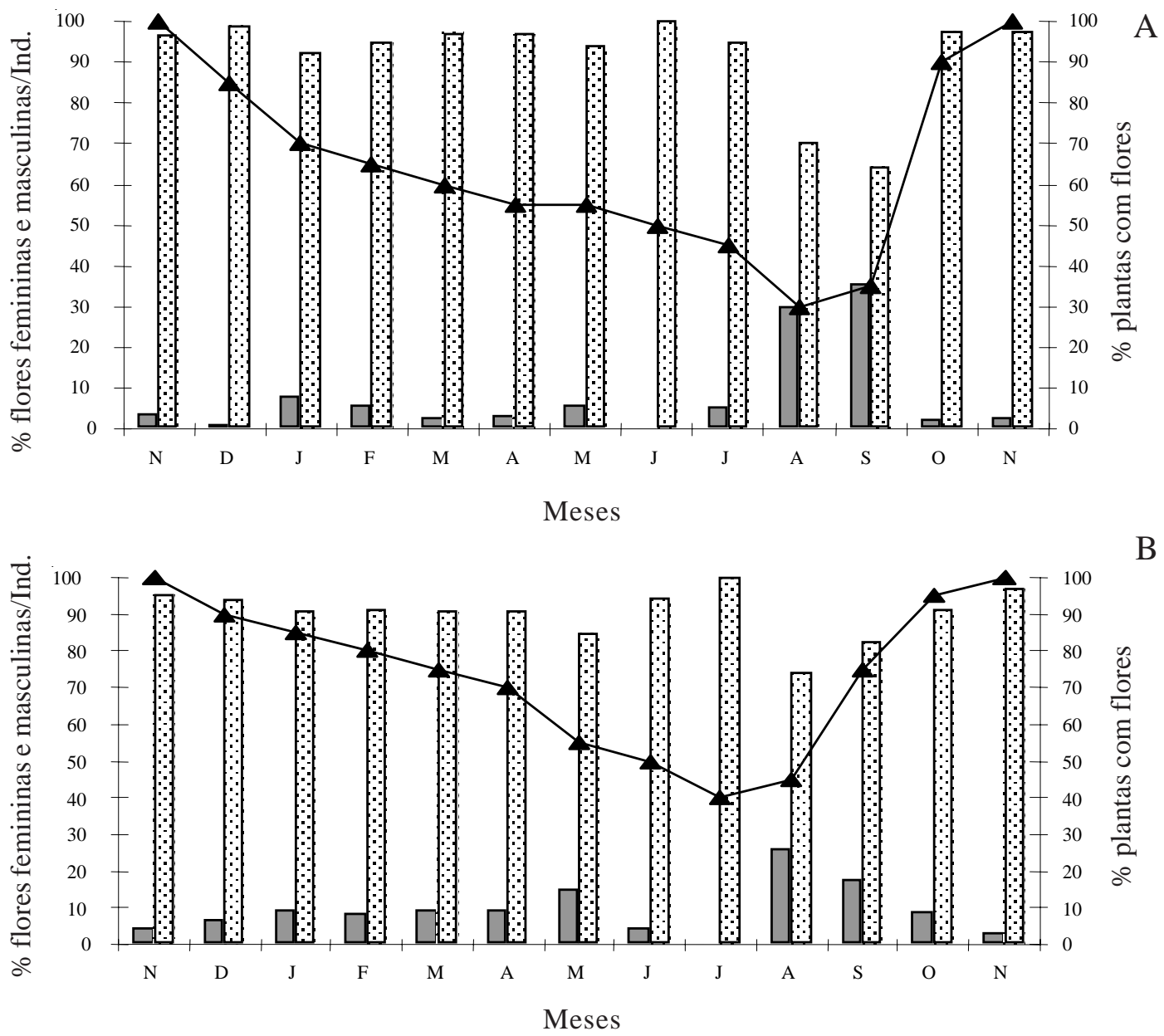

B

Figura 1. Fenologia da floração de Jatropha mutabilis (A) e de J. mollissima (B). $\quad \square=\%$ flores $\quad$; $\quad$ : $=\%$ flores $\sigma^{*}$; $\Delta=\%$ indivíduos com flores.

Figure 1. Flowering phenology of Jatropha mutabilis (A) and J. mollissima (B). $\square=\%$ flowers $\%$; $=\%$ flowers $0^{*}$; $\Delta=\%$ flowering individuals. 
produziram frutos. Durante o mês de janeiro a produção atingiu seu valor máximo, com $100 \%$ dos indivíduos frutificando. O fruto é do tipo cápsula tricoca loculicida, de deiscência explosiva, tendo inicialmente coloração verde e adquirindo, com a maturação, coloração marrom. Durante todo o período de frutificação foram observadas, tanto em J. mutabilis como em J. mollissima, formigas do gênero Solenopsis Westwood (1840) (Myrmicinae) retirando elaiossomos das sementes dispersas primariamente por explosão. Atributos florais - As inflorescências de J. mutabilis e J. mollissima são terminais, cimosas, monóicas, com flores femininas sempre centrais e as masculinas dispostas externamente às femininas, sendo o número de flores masculinas superior ao de femininas (tabela 1).

As inflorescências de $J$. mutabilis têm duração média de 20 dias. A primeira flor a abrir na inflorescência é sempre feminina e, após o seu murchamento, os demais botões abrem-se sucessivamente, alternando flores masculinas com femininas. Em uma mesma inflorescência, podem ser encontradas até oito flores masculinas abertas, diariamente, abrindo-se, no máximo, uma flor feminina por dia (tabela 1), estando a inflorescência funcionalmente masculina ou feminina. Em J. mollissima as inflorescências apresentam duração média de 30 dias. Inicialmente abrem-se uma a três flores femininas em um mesmo dia (tabela 1) e, após a senescência destas, abrem-se, alternadamente, flores masculinas e flores femininas. Em ambas as espécies, raramente encontram-se os dois tipos de flores na mesma inflorescência (figura 2A).

As flores de J. mutabilis e J. mollissima são actinomorfas, do tipo disco (sensu Faegri \& Pijl 1979), apresentam cálice verde com máculas avermelhadas e emitem odor suave e adocicado.

Jatropha mutabilis possui corola de coloração vermelho intenso contrastando com o androceu amarelo das flores masculinas e o gineceu amarelo-esverdeado das flores femininas. As flores de J. mollissima apresentam corola amarela com máculas rosadas a avermelhadas, enquanto que o androceu e gineceu possuem coloração amarelada. $\mathrm{O}$ androceu, nas duas espécies, é constituído por oito estames, sendo bisseriados em J. mollissima, com cinco estames externos e três internos. Em ambas as espécies as anteras apresentam deiscência rimosa e o gineceu é formado por três estiletes com estigmas bífidos, sendo o ovário súpero e globoso contendo três óvulos.

Entre as flores masculinas e femininas de J. mutabilis e J. mollissima observam-se várias diferenças, algumas das quais estão relacionadas na tabela 1. O nectário das flores femininas das espécies estudadas é um disco, localizado na base do ovário, onde o néctar se acumula. O nectário das flores masculinas de J. mutabilis é formado por cinco glândulas soldadas na base, envolvendo a porção basal dos filetes. Nas flores masculinas de J. mollissima o nectário também é constituído por cinco glândulas que, no entanto, encontram-se livres.

Durante os estudos de campo, dois indivíduos de J. mutabilis apresentaram flores em estágio intermediário de sexualidade, com vestígios do sexo oposto. Em um deles foram encontradas algumas flores em que o gineceu e os nectários eram semelhantes aos de uma flor feminina, no entanto apresentavam ainda um androceu rudimentar, constituído por oito estames radiais, mas com anteras menores $(3 \mathrm{~mm})$ que as das flores masculinas ( $6 \mathrm{~mm}$ ) e com grãos de pólen viáveis

Tabela 1. Principais diferenças entre flores masculinas e femininas de Jatropha mutabilis e de J. mollissima.

Table 1. Main differences between male and female flowers of Jatropha mutabilis and J. mollissima.

\begin{tabular}{|c|c|c|c|c|c|c|c|}
\hline Flores & $\begin{array}{l}\text { Botões/ } \\
\text { inflor. }\end{array}$ & $\begin{array}{l}\text { Flores } \\
\text { abertas/ } \\
\text { infl./dia }\end{array}$ & $\begin{array}{l}\text { Diâmetro } \\
\text { corola } \\
(\mathrm{mm})\end{array}$ & $\begin{array}{l}\text { Duração } \\
\text { flor } \\
\text { (horas) }\end{array}$ & $\begin{array}{l}\text { Conc. açúc. } \\
\text { néctar } \\
(\%)^{*}\end{array}$ & $\begin{array}{l}\text { Volume } \\
\text { néctar } \\
(\mu \mathrm{L})^{*}\end{array}$ & Tipo de nectário \\
\hline \multicolumn{8}{|c|}{ J. mutabilis } \\
\hline $0^{\pi}$ & $16-64$ & $1-8$ & $26-27$ & 12 & $26-27$ & $6-10$ & \multirow{2}{*}{$\begin{array}{c}5 \text { glândulas } \\
\text { soldadas na base } \\
\text { disco }\end{array}$} \\
\hline q & $3-6$ & 1 & $25-28$ & 36 & $29-32$ & $12-16$ & \\
\hline \multicolumn{8}{|c|}{ J. mollissima } \\
\hline $0^{\pi}$ & $20-48$ & $1-10$ & $18-20$ & 12 & $20-23$ & $8-10$ & \multirow{2}{*}{$\begin{array}{c}5 \text { glândulas livres } \\
\text { disco }\end{array}$} \\
\hline q & $3-6$ & $1-3$ & $21-24$ & 36 & $25-28$ & $14-16$ & \\
\hline
\end{tabular}

* Medidas realizadas às 9:00 h. 
(80\%). No entanto, o "pollenkitt" apresentou-se em menor quantidade que nas anteras das flores masculinas e, apesar do pólen viável, as anteras permaneceram fechadas ao longo de toda a antese. No outro indivíduo ocorreu o inverso, foram encontradas algumas flores com androceu e nectários semelhantes aos das flores masculinas, mas que apresentavam um gineceu atrofiado, apesar de conter o mesmo número de óvulos das flores femininas. Após a observação dessas flores, esses indivíduos foram monitorados durante sete meses, não voltando a apresentar flores com vestígios do sexo oposto.

Antese, produção de néctar e caracteres polínicos Jatropha mutabilis e J. mollissima possuem antese diurna que se inicia por volta das 4:00 - 4:30 h. Em ambas as espécies a duração do processo de antese varia bastante entre as flores femininas e masculinas (tabela 1). As flores masculinas permanecem abertas por 12 horas, após iniciada a antese, quando começam a murchar, desprendendo-se então da planta através de uma articulação existente entre o receptáculo e o pedicelo. As flores femininas podem permanecer abertas por até 36 horas após o início da antese, entretanto, quando ocorre a polinização, algumas pétalas podem desprender-se do receptáculo antes desse período. A deiscência das anteras e a exposição dos grãos de pólen, nas espécies estudadas, ocorrem por volta de uma hora após o início da antese. Porém, a partir das observações de campo, pôde-se verificar que, em dias chuvosos, a deiscência das anteras só ocorre por volta de uma hora após ter cessado a chuva. Os estigmas tornam-se receptivos, também, a partir de uma hora após o início

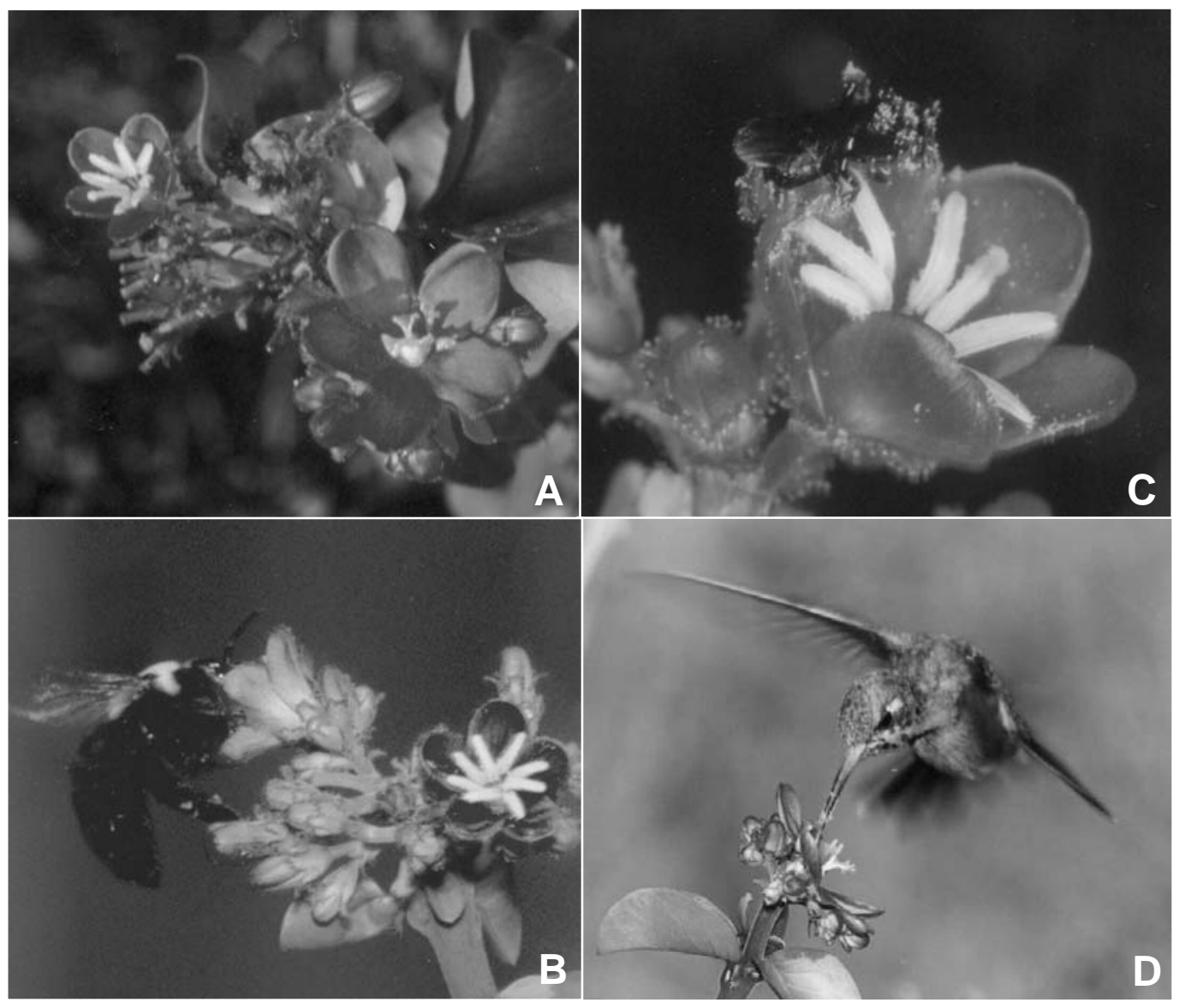

Figura 2. Flores e visitantes florais de Jatropha mutabilis. A. Flor feminina e masculina em antese simultânea em uma mesma inflorescência. B. Xylocopa grisescens visitando flor masculina. C. Trigona spinipes em flor masculina. D. Chlorostilbon aureoventris visitando flor feminina.

Figure 2. Flowers and visitors of Jatropha mutabilis. A. Female and male flowers in simultaneous anthesis in a same inflorescence. B. Xylocopa grisescens visiting a male flower. C. Trigona spinipes in a male flower. D. Chlorostilbon aureoventris visiting a female flower. 
da antese, permanecendo assim até o murchamento da flor, quando adquirem coloração marrom.

A produção do néctar nas duas espécies inicia-se cerca de uma hora após o início da antese, tanto nas flores femininas como nas masculinas. Os valores de concentração e volume do néctar de flores femininas e masculinas encontram-se na tabela 1. Até às 9:00 h o volume alcança seu valor máximo $(16 \mu \mathrm{L})$, após o que a quantidade de néctar disponível diminui (mesmo em flores privadas de visitas) e a concentração de açúcares aumenta. Às 12:00 h o volume de néctar em J. mutabilis foi cerca de $4 \mu \mathrm{L}$ nas flores masculinas e cerca de $5 \mu \mathrm{L}$ nas femininas. Em J. mollissima, nesse mesmo horário, o volume de néctar foi ca. $2 \mu \mathrm{L}$ e $4 \mu \mathrm{L}$, respectivamente nas flores masculinas e femininas. Para as duas espécies a concentração de açúcares no néctar nas flores dos dois sexos, às 12:00 h, foi superior a $62 \%$. Nas flores femininas de ambas as espécies, que duram até 36 horas, não houve produção de néctar durante a noite e apenas na manhã seguinte voltou a produzí-lo.

A viabilidade polínica foi de cerca de $97 \%$ em J. mutabilis e $100 \%$ em J. mollissima. Os grãos de pólen de ambas as espécies encontram-se mergulhados em um fluído lipídico como indicado em outros trabalhos (Endress 1994, Machado \& Lopes 2000), não constituindo apenas um filme lipídico envolvendo os graõs (pollenkitt sensu Hesse 1981). Cada flor masculina de J. mutabilis produziu ca. 1.400 grãos de pólen, enquanto que as de J. mollissima ca. 5.400 grãos. A razão pólen/óvulo (sensu Cruden 1977) foi, então, respectivamente, 466,7 e 1.800, uma vez que as flores apresentam três óvulos.

Sistema reprodutivo - Os resultados referentes ao sistema reprodutivo demonstraram que nas duas espécies não ocorre apomixia nem polinização pelo vento e que ambas são autocompatíveis, uma vez que houve formação de frutos a partir dos testes de geitonogamia (tabela 2). No entanto, as maiores taxas de frutificação foram obtidas nos testes de xenogamia (tabela 2), sendo observada diferença significativa entre os valores de geitonogamia e xenogamia em J. mollissima $\left(\mathrm{F}^{2}=5,62\right.$; $\mathrm{GL}=1 ; \mathrm{p}<0,025)$, o que indica que a espécie é preferencialmente xenógama, o mesmo não tendo sido encontrado para J. mutabilis. Em ambas as espécies, tanto nos tratamentos de geitonogamia como nos de xenogamia ou mesmo em condições naturais, todos os frutos obtidos desenvolveram três sementes. O total desenvolvimento do fruto ocorreu cerca de 40 dias após a fecundação.

Visitantes florais - Os visitantes das flores de J. mutabilis e J. mollissima comportaram-se de modo semelhante em flores masculinas e femininas. Nas duas espécies estudadas o maior número de visitas ocorreu nas primeiras horas da manhã (5:00-11:00 h), ocorrendo apenas visitas esporádicas de algumas espécies à tarde (tabela 3).

As abelhas Eulaema nigrita e Xylocopa grisescens e os beija-flores Amazilia sp., Chlorostilbon aureoventris e Chrysolampis mosquitus, foram considerados os polinizadores mais eficientes dentre os visitantes às flores de J. mutabilis devido ao comportamento e freqüência de visitas. Em J. mollissima o comportamento e a freqüência das abelhas, borboletas e da vespa, Polybia ignobilis, indicam que estes foram os principais polinizadores desta espécie (tabela 3).

Eulaema nigrita e X. grisescens (figura 2B) visitaram as flores de J. mutabilis para coletar néctar. Devido ao grande porte, essas abelhas utilizam, nas flores femininas, as pétalas e os estigmas como

Tabela 2. Resultados dos tratamentos para verificação do sistema reprodutivo e da formação de frutos em condições naturais (controle) em Jatropha mutabilis e J. mollissima.

Table 2. Results of the treatments for checking reproductive system and fruit set under natural conditions (control) in Jatropha mutabilis and J. mollissima.

\begin{tabular}{|c|c|c|c|c|}
\hline \multirow[t]{2}{*}{ Tratamentos } & \multicolumn{2}{|c|}{ Jatropha mutabilis } & \multicolumn{2}{|c|}{ Jatropha mollissima } \\
\hline & Flores/Frutos & Sucesso & Flores/Frutos & Sucesso \\
\hline Apomixia & $20 / 0$ & 0 & $20 / 0$ & 0 \\
\hline Polinização pelo vento & $10 / 0$ & 0 & $13 / 0$ & 0 \\
\hline Geitonogamia & $20 / 12$ & 60 & $20 / 13$ & 65 \\
\hline Xenogamia & $20 / 16$ & 80 & $20 / 19$ & 95 \\
\hline Controle & $20 / 15$ & 75 & $20 / 17$ & 85 \\
\hline
\end{tabular}


Tabela 3. Visitantes florais, horário, duração e comportamento de visita às flores de Jatropha mutabilis e Jatropha mollissima.

Table 3. Floral visitors, time and length of visits and visiting behaviour in Jatropha mutabilis and Jatropha mollissima flowers.

\begin{tabular}{|c|c|c|c|}
\hline Visitantes & $\begin{array}{l}\text { Duração da } \\
\text { visita (seg.) }\end{array}$ & Horário de visitas & Resultado da visita \\
\hline \multicolumn{4}{|c|}{ Jatropha mutabilis } \\
\hline \multicolumn{4}{|l|}{ ABELHAS (APIDAE) } \\
\hline Apis mellifera (Linnaeus, 1758) & $6-12$ & 5:00-11:00 & polinizador ocasional \\
\hline Eulaema nigrita (Lepeletier, 1841) & $4-5$ & 5:00-10:00 & polinizador efetivo \\
\hline Trigona spinipes (Fabricius, 1793) & $20-60$ & 5:00-16:00 & polinizador ocasional \\
\hline Xylocopa grisescens (Lepeletier, 1841) & $2-5$ & 5:30-11:00 & polinizador efetivo \\
\hline \multicolumn{4}{|l|}{ BEIJA-FLORES (TROCHILIDAE) } \\
\hline Chlorostilbon aureoventris (d'Orbigny \& Lafresnaye, 1838) & $1-2$ & 5:00-16:00 & polinizador efetivo \\
\hline Amazilia sp. & $1-2$ & 4:40-16:00 & polinizador efetivo \\
\hline Chrysolampis mosquitus (Linnaeus, 1758) & $1-2$ & 5:00-16:00 & polinizador efetivo \\
\hline \multicolumn{4}{|l|}{ BORBOLETA(PIERIDAE) } \\
\hline Phoebis sp. & $10-15$ & 7:00-16:00 & pilhador \\
\hline \multicolumn{4}{|l|}{ VESPA(VESPIDAE) } \\
\hline \multirow[t]{2}{*}{ Polybia paulista (Ihering, 1896) } & $30-50$ & 5:00-16:00 & polinizador ocasional \\
\hline & \multicolumn{3}{|c|}{ atropha mollissima } \\
\hline \multicolumn{4}{|l|}{ ABELHAS (APIDAE) } \\
\hline Apis mellifera (Linnaeus, 1758) & $6-12$ & $5: 00-11: 00$ & polinizador efetivo \\
\hline Eulaema nigrita (Lepeletier, 1841) & $3-6$ & 5:00-10:00 & polinizador efetivo \\
\hline Trigona spinipes (Fabricius, 1793) & $20-60$ & 5:00-11:00 & polinizador efetivo \\
\hline \multicolumn{4}{|l|}{ BORBOLETAS (PIERIDAE) } \\
\hline Anteos clorinde (Godart, [1824]) & $8-18$ & $8: 00-1600$ & polinizador efetivo \\
\hline Ascia monuste (Linnaeus, 1764) & $5-12$ & $6: 30-15: 00$ & polinizador efetivo \\
\hline Ascia sp. & $4-15$ & 7:00-17:00 & polinizador efetivo \\
\hline Phoebis sennae (Linnaeus, 1758) & $8-20$ & 7:00-17:00 & polinizador efetivo \\
\hline Phoebis sp. & $10-15$ & 7:00-17:00 & polinizador efetivo \\
\hline \multicolumn{4}{|l|}{ VESPAS (VESPIDAE) } \\
\hline Polybia ignobilis (Haliday, 1836) & $20-40$ & $5: 30-16: 00$ & polinizador efetivo \\
\hline Polybia paulista (Ihering, 1896) & $30-50$ & $5: 00-16: 00$ & polinizador ocasional \\
\hline \multicolumn{4}{|l|}{ MOSCA } \\
\hline Indeterm. sp. 1 & $10-40$ & $5: 00-10: 00$ & pilhador \\
\hline
\end{tabular}

plataforma de pouso e nas flores masculinas, que são menores que as femininas, além da flor visitada, parte da inflorescência também serve como plataforma de pouso. As regiões tanto de deposição dos grãos de pólen no corpo, quanto de contato com os estigmas foram a parte superior da cabeça e a porção ventral do tórax. Essas abelhas visitaram várias flores da mesma ou de diferentes inflorescências, permanecendo nas flores por intervalos variados (tabela 3). Abelhas fêmeas de E. nigrita também visitaram as flores de J. mollissima (tabela 3), apresentando comportamento semelhante ao observado em J. mutabilis.
Apis mellifera L. e Trigona spinipes (figura 2C), comportaram-se de maneira semelhante nas duas espécies estudadas, iniciando suas visitas por volta das 5:00 h, coletando pólen ou néctar. Essas abelhas aproximaram-se das flores frontalmente, pousando diretamente nas pétalas. Nas flores femininas, dirigiram-se ao nectário, para coletar néctar. Nas flores masculinas, apresentaram dois tipos de comportamento distintos: nas visitas para coleta de néctar, introduziram a cabeça entre as anteras e as pétalas, em direção ao nectário, ficando com o corpo repleto de grãos de pólen proveniente das anteras e também das pétalas. Para 
coletar pólen, as abelhas pousaram diretamente nas anteras, manipulando-as com o primeiro par de pernas. Essas abelhas visitaram em média duas a três flores por inflorescência, após o que, em vôo pairado, transferiram os grãos de pólen para as corbículas. Em J. mutabilis elas não foram consideradas polinizadores efetivos, uma vez que dificilmente contataram os estigmas durante as visitas às flores femininas. Entretanto, pelo fato das flores de J. mollissima serem menores que as de $J$. mutabilis, tanto A. mellifera quanto $T$. spinipes, contataram frequientemente as partes reprodutivas das flores sendo, portanto, consideradas polinizadores efetivos.

As flores de ambas as espécies estudadas foram visitadas por Polybia paulista (tabela 3), que iniciou suas visitas $\log$ o nas primeiras horas da manhã, estendendo-as até às 16:00 h. Inicialmente aproximouse da inflorescência, pousou na flor e coletou néctar. Nas flores masculinas os estames e as pétalas serviram como plataforma de pouso, sendo as anteras tocadas pela a porção ventral do tórax e do abdômen. Durante visitas às flores femininas, essa vespa pousou nas pétalas para coletar néctar e, devido ao seu pequeno tamanho, apenas esporadicamente tocou os estigmas. Outra espécie de vespa, Polybia ignobilis, foi registrada visitando apenas as flores de $J$. mollissima (tabela 3 ). Durante as visitas, para coleta de néctar, contatou os órgãos reprodutivos das flores masculinas e femininas, com toda parte ventral do corpo. Visitou várias flores de uma mesma inflorescência, bem como flores das outras inflorescências.

As três espécies de beija-flores, $C$. aureoventris (figura 2D), Amazilia sp. e C. mosquitus, visitaram apenas as flores de J. mutabilis (tabela 3), apresentando comportamento semelhante, sendo consideradas polinizadores efetivos. As visitas iniciaram-se entre 40 e 60 min. após iniciada a antese, estendendo-se até às 16:00 h, sendo, entretanto, mais frequientes até às 11:00 h. Nas primeiras horas da tarde não foram observadas visitas; apenas por volta das 15:00 $\mathrm{h}$ às 16:00 $\mathrm{h}$ os beijaflores voltaram a realizar visitas esporádicas às flores de J. mutabilis. As visitas às flores foram rápidas, com duração máxima de dois segundos. Inicialmente os beijaflores pairaram defronte à flor e, durante a coleta de néctar, tocaram com o bico tanto no estigma, das flores femininas, como nas anteras, das masculinas. Visitaram, em geral, várias flores em um mesmo indivíduo. Entre uma visita e outra dos beija-flores, houve um intervalo com uma variação de 40 a 50 minutos.

Phoebis sp. (Lepidoptera) visitou esporadicamente as flores de J. mutabilis para coletar néctar. Nas flores masculinas, tocou as anteras com a probóscide e o primeiro par de pernas. Nas flores femininas, no entanto, raramente contatou as superfícies estigmáticas, comportando-se como pilhador.

Anteos clorinde, Ascia monuste, Ascia sp., Phoebis sennae e Phoebis sp. visitaram as flores de J. mollissima durante todo o dia, entretanto, no período entre 12:00 h e 14:00 $\mathrm{h}$ a freqüência de visitas diminuiu bastante. As cinco espécies de borboletas apresentaram comportamento de visita semelhante, utilizando as pétalas como plataforma de pouso. Durante a coleta de néctar tocaram as anteras e os estigmas com o primeiro par de pernas, a probócide e/ou as asas.

A espécie de mosca, visitante das flores de J. mollissima, aproximou-se rapidamente, abordando principalmente as inflorescências mais altas, sendo mais freqüente nas primeiras horas da manhã. Durante a coleta de néctar raramente contatou os estigmas, sendo considerada como pilhadora.

Ao longo do ano ocorreu variação dos grupos de polinizadores de J. mutabilis (figura 3), sendo calculada a taxa de formação de frutos em condições naturais, durante os períodos em que as classes de polinizadores foram diferentes ou se sobrepuseram. Em janeiro de 2000, período no qual apenas foram registradas visitas de abelhas, a taxa de formação de frutos em condições naturais foi de $75 \%$. No mês de maio, quando foram registrados apenas beija-flores, a taxa de formação de frutos foi de $70 \%$. Por fim, em outubro, quando foram observadas visitas tanto de abelhas como de beija-flores,

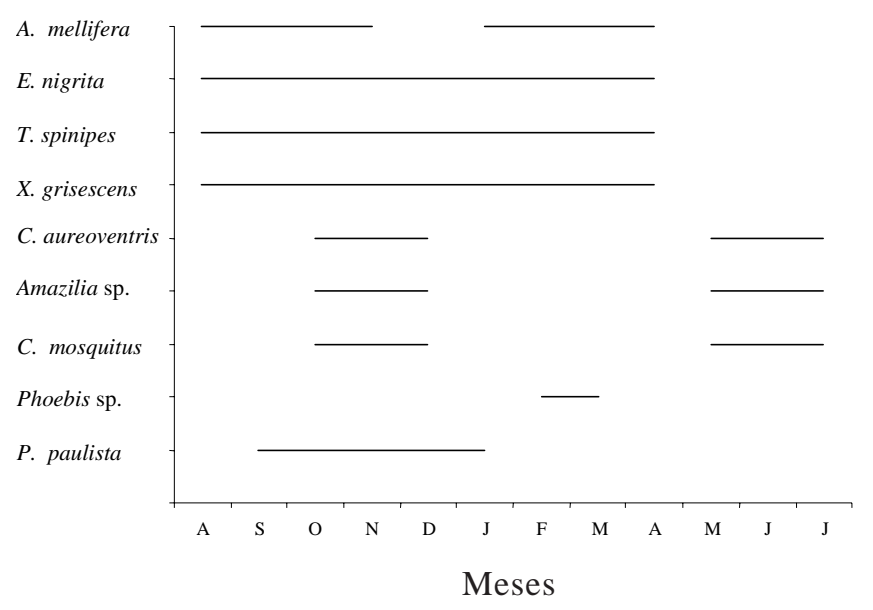

Figura 3. Sazonalidade dos visitantes florais de Jatropha mutabilis.

Figure 3. Seasonality of the floral visitors of Jatropha mutabilis. 
a taxa de formação de frutos foi de $75 \%(\mathrm{~N}=20$, para cada tratamento).

\section{Discussão}

Fenologia reprodutiva - Jatropha mutabilis (Pohl) Baill. e J. mollissima (Pohl) Baill. possuem padrão de floração do tipo contínuo (sensu Newstrom et al. 1994). Espécies com esse tipo de floração produzem flores ao longo de todo o ano, cessando a produção, esporadicamente, durante breves períodos. Determinar precisamente o pico de floração para as espécies estudadas é difícil, uma vez que os períodos de maior produção de flores femininas e masculinas são distintos. A maior produção de flores femininas e a queda no número de flores masculinas, provavelmente estão relacionadas ao surgimento das novas inflorescências, nas quais as primeiras flores a se abrirem são femininas. A maior produção de flores masculinas, que ocorreu nos meses de outubro e novembro, coincide com o maior percentual de indivíduos floridos. Em Jatropha gossypifolia L. a floração é do tipo cíclica, com a espécie florescendo ao longo do ano, ocorrendo a cada dois meses um pico de floração (Ormond et al. 1984). Machado et al. (1997) observaram, em Serra Talhada (PE), que J. mollissima frutifica por um longo período do ano, cerca de nove meses, no entanto, os dados fenológicos nesse trabalho mostram que a espécie não permanece florida durante todo o ano, como foi observado nos indivíduos localizados em Arcoverde (PE). Provavelmente a diferença entre os dados coletados em Serra Talhada e Arcoverde está associada à disponibilidade das chuvas, uma vez que a precipitação em Serra Talhada é mais baixa e a fenologia de plantas de Caatinga está diretamente relacionada com este fator (Machado et al. 1997).

Atributos florais - Jatropha mutabilis e J. mollissima possuem atributos florais (simetria radial, tipo disco, odor suave, antese diurna), que são característicos da síndrome de melitofilia (sensu Faegri \& Pijl 1979, Proctor et al. 1996). Entretanto, a coloração vermelha da corola de J. mutabilis é geralmente associada à polinização por beija-flores (Faegri \& Pijl 1979, Endress 1994, Proctor et al. 1996). É referido na literatura que as abelhas são sensíveis apenas aos comprimentos de onda correspondentes ao ultravioleta, azul e verde-amarelo, não distinguindo a cor vermelha, a menos que exista um padrão de reflexão de ultravioleta associado a essa cor (Faegri \& Pijl 1979, Proctor et al. 1996). Chittka \& Waser (1997), contudo, contestam essa afirmativa, mencionando que o espectro de visão das abelhas estaria dentro de um longo comprimento de onda, incluindo o vermelho. Não verificamos se há ou não reflexão de ultravioleta em J. mutabilis, mas detectamos a presença de abelhas nas flores durante nove meses do ano. Os beija-flores visitaram as flores por seis meses, durante três dos quais ocorreram em sobreposição com as abelhas e nos demais três meses foram os únicos visitantes. Flores de J. integerrima Jacq., também com pétalas de coloração vermelha, são visitadas por abelhas, embora estas sejam pilhadoras (Epila-Otara 1993).

Antese, produção de néctar e caracteres polínicos - A duração das flores de J. mutabilis e J. mollissima varia entre os dois sexos, tendo as flores masculinas um período de vida mais curto que as flores femininas. Segundo Primack (1985), existe uma tendência em espécies monóicas de que flores femininas apresentem maior longevidade que flores masculinas, o que aumentaria a probabilidade de ocorrência de polinização.

De acordo Lloyd \& Webb (1986), a protoginia, mecanismo de separação temporal que reduz a autopolinização ou geitonogamia, ocorre tanto em nível intrafloral, em espécies hermafroditas, como interfloral, em espécies monóicas e dióicas. Jatropha mutabilis e J. mollissima apresentam padrão de protoginia interfloral, uma vez que as primeiras flores a se abrirem numa inflorescência são sempre femininas. Ormond et al. (1984) também classificam J. gossypifolia como protogínica. Segundo Bertin \& Newman (1993), protoginia ocorre em muitas espécies monóicas e a polinização anemófila é comum em espécies que apresentam padrão de protoginia interfloral associada com flores muito pequenas e inconspícuas. Entretanto, no presente estudo, apesar das espécies estudadas serem monóicas e protogínicas, suas flores são bastante vistosas, sendo a polinização exclusivamente biótica.

O néctar, em flores tipo disco, geralmente fica exposto, sendo de fácil acesso para muitos insetos como moscas, abelhas e vespas, entre outros (Proctor et al. 1996). O gênero Jatropha normalmente apresenta flores tipo disco, com nectários centrais e acessíveis, podendo ser visitadas por vários insetos, sendo a maioria das suas espécies considerada entomófila (Dehgan \& Webster 1979), semelhante ao verificado no presente estudo e no de Reddi \& Reddi (1983), que estudaram J. gossypifolia L.

A concentração de açúcares no néctar das flores varia entre as espécies de plantas, estando geralmente relacionada com a classe de animais que as visitam (Baker 1975, Proctor et al. 1996). Em espécies melitófilas a concentração de açúcares no néctar varia entre $16 \%$ e $50 \%$, nas ornitófilas a variação é de $13 \%$ a 
$30 \%$ e nas espécies psicófilas, de $13 \%$ a $44 \%$ (Baker 1975). A concentração de açúcares no néctar em J. mutabilis e J. mollissima abrange todas essas classes de polinizadores, favorecendo visitas tanto por abelhas como por outros grupos de visitantes florais.

O aumento na concentração de açúcares no néctar e a diminuição no volume ao longo do dia, fatos que foram registrados para ambas as espécies estudadas, provavelmente estão relacionados com o aumento da temperatura (Faegri \& Pijl 1979, Baker \& Baker 1983). Machado \& Sazima (1995) observaram que a variação de volume e concentração de açúcares no néctar ao longo do dia em Ruellia asperula Lindau (Acanthaceae), uma espécie também de Caatinga polinizada por beija-flores, poderia estar relacionada às mudanças de temperatura e umidade do ar.

Em J. mutabilis e J. mollissima cerca de $90 \%$ das flores produzidas ao longo do ano são masculinas. Em espécies monóicas, a disponibilidade de recursos florais varia bastante entre flores masculinas e femininas (Willson \& Ågren 1989). Em geral, a maior parte dos recursos florais é produzida pelas flores masculinas, principalmente se for analisado em termos de indivíduos, uma vez que em espécies monóicas ou dióicas, normalmente o número de flores masculinas é superior ao número de flores femininas (Willson \& Ågren 1989, Proctor et al. 1996, Lopes \& Machado 1998).

O "pollenkitt" está presente em todas as Angiospermas, sendo definido, conforme mencionado anteriormente, como um filme de substâncias lipídicas que envolve os grãos de pólen (Hesse 1981). Segundo Endress (1994), "pollenkitt" em excesso é típico de plantas zoófilas contribuindo para a agregação dos grãos de pólen, bem como para a aderência deles ao corpo dos visitantes, tornando o transporte do pólen e sua deposição na superfície estigmática mais eficientes. Assim como para as espécies de Jatropha estudadas, Ormond et al. (1984) observaram também gotas de origem lipídica sobre a superfície dos grãos de pólen de J. gossypifolia.

Sistema reprodutivo - Apesar das espécies estudadas serem autocompatíveis, reproduzindo-se por geitonogamia e xenogamia, testes estatísticos indicam que J. mollissima é preferencialmente xenógama. Embora a espécie tenha produzido frutos nos tratamentos de geitonogamia, as chances de que este fato ocorra na natureza são pequenas, pois raramente são encontradas flores femininas e masculinas abertas concomitantemente numa mesma inflorescência. Com relação à razão pólen/óvulo, segundo a classificação de
Cruden (1977), J. mutabilis e J. mollissima seriam classificadas como xenógamas facultativas.

A presença de flores com vestígios do sexo oposto foi rara em J. mutabilis. Gallindo (1985) relata que estaminódios podem ocorrer em flores femininas de J. mutabilis e J. gossypifolia. A produção de flores morfologicamente "hermafroditas" em J. mutabilis não tem significado ecológico claro, uma vez que apesar da alta taxa de viabilidade polínica em um dos tipos de flores morfologicamente "hermafroditas" (cujo gineceu era semelhante do das femininas e o androceu apresentava anteras menores que as das flores masculinas), as anteras encontravam-se fechadas durante toda a antese floral, o que as tornava funcionalmente femininas. $\mathrm{O}$ mesmo ocorreu no outro tipo de flores "hermafroditas", em que $\mathrm{o}$ androceu era semelhante ao das masculinas $\mathrm{e}$ o gineceu atrofiado, as quais atuavam como masculinas. Visitantes florais e polinização - A polinização de J. mutabilis e J. mollissima é estritamente biótica. Embora muitos autores relacionem monoicia com polinização pelo vento (Faegri \& Pijl 1979, Primack 1985), em florestas tropicais a maioria das espécies monóicas é zoófila (Bawa \& Beach 1981), sendo polinizadas por insetos ou beija-flores. Dentro da família Euphorbiaceae, algumas espécies de Croton são anemófilas (Tejada \& Bullock 1988, Dominguez \& Bullock 1989, Passos 1995), enquanto outras, como Croton bonplandianum e Phyllanthus pinnatus, são polinizadas tanto pelo vento como por insetos, sendo a polinização anemófila mais significativa (Reddi \& Reddi 1985).

Jatropha mutabilis é polinizada efetivamente por abelhas e beija-flores, possuindo várias características florais comuns à síndrome de melitofilia (Faegri \& Pijl 1979). A cor vermelha das pétalas parece ser o principal fator a atrair os beija-flores para as flores de J. mutabilis. Jatropha mollissima é uma espécie melitófila, sendo polinizada por abelhas e vespas mas, também, ocasionalmente por borboletas.

Trigona spinipes e Apis mellifera, apesar de terem sido consideradas como polinizadores ocasionais de J. mutabilis, podem favorecer a polinização cruzada, uma vez que ao diminuírem a quantidade de néctar disponível, forçam os polinizadores efetivos a visitar maior número de flores (Camargo et al. 1984).

Ao contrário de Polybia paulista, que é um polinizador ocasional nas duas espécies estudadas, P. ignobilis, visitante apenas das flores de J. mollissima, é um importante polinizador dessa espécie devido ao comportamento de visita e ao seu tamanho adequado. 
As vespas, que visitam flores para coletar néctar, atuam, em geral, apenas como polinizadores ocasionais por serem pouco especializadas no transporte dos grãos de pólen (Percival 1965, Endress 1994). Em J. mollissima o fluido lipídico que envolve os grãos aumenta a capacidade dos grãos de pólen aderirem ao corpo de visitantes como P. ignobilis. Em Vismia guianensis (Aubl.) Choisy (Clusiaceae), Polybia sp. foi considerada também como polinizador efetivo por possuir pêlos na face ventral do abdômen (Santos \& Machado 1998), o que não foi observado, aqui, para $P$. ignobilis.

Apesar de J. mutabilis e J. mollissima não possuírem as características típicas das síndromes de ornitofilia e psicofilia, são polinizadas também, conforme visto, por beija-flores e borboletas, respectivamente. Entretanto, todos os beija-flores que visitaram J. mutabilis são generalistas. Em áreas de Cerrado, por exemplo, Oliveira (1998) concluiu que o número total de plantas visitadas por beija-flores inclui espécies tipicamente ornitófilas, mas também com outras síndromes florais. O fato da disponibilidade de recursos florais na Caatinga estar diretamente relacionada com a escassez de períodos chuvosos e os recursos florais de J. mutabilis e J. mollissima serem de fácil acesso, induz a que vários grupos utilizem suas flores como fontes para obtenção de energia.

Com relação ao uso de recursos florais de J. mutabilis por abelhas e beija-flores, a falta de visitas de abelhas durante três meses (maio-julho) provavelmente está associada à floração, nesses meses, de outras espécies melitófilas (Centrosema spp. e Senna spp., entre outras). Nesse período foram registradas apenas visitas de beija-flores em J. mutabilis. Nos meses de outubro a dezembro, quando cerca de $90 \%$ dos indivíduos de J. mutabilis encontravam-se floridos, pôde-se observar visitas simultâneas de abelhas e beijaflores, provavelmente devido ao aumento da oferta de recursos pela espécie estudada e a escassez de outras fontes de energia para as espécies visitantes de abelhas e beija flores. A alta taxa de formação natural de frutos, observada durante os diferentes períodos de visitas dos distintos polinizadores, indica que tanto as abelhas quanto os beija-flores são igualmente eficientes como polinizadores de J. mutabilis. Reddi \& Reddi (1983) também observaram sazonalidade dos visitantes às flores de J. gossypifolia, os quais, durante o período no qual ocorria diminuição na produção do número de flores, buscavam recursos florais de outras espécies floridas.

A Caatinga caracteriza-se por ser um ambiente onde as condições climáticas são extremas, o que diminui a oferta de recursos florais durante parte do ano (Aguiar et al. 1995). O fato das duas espécies de Jatropha estudadas serem típicas de áreas de Caatinga e permanecerem floridas durante todo o ano torna as mesmas importantes fontes de energia para a manutenção dos animais que se alimentam de pólen e néctar, principalmente nos períodos de estiagem, quando há pouca disponibilidade de recursos florais. Em contrapartida, por serem, J. mutabilis e J. mollissima, espécies monóicas e não agamospérmicas, a presença e eficácia dos seus polinizadores são fundamentais para a reprodução e manutenção de suas populações.

Agradecimentos - Aos Drs. Antônio Carlos Weber, Inara Leal, Gladys Flávia de Pinna e Iracema Loyola, pela leitura crítica e sugestões ao manuscrito, quando ainda em forma de dissertação; Djnaldo Galindo, Felipe Pimentel, Paulo Sávio Damásio, Raquel Carvalho e Vaneicia Gomes pela ajuda no trabalho de campo; CNPq pelo apoio financeiro a M. Santos (Bolsa de Mestrado), I. Machado e A. Lopes (Bolsas de Produtividade em Pesquisa); Sr. Manoel Leite, pela permissão para realização de parte deste trabalho em sua propriedade no Vale do Catimbau, Sr. Valdir Brito, por autorizar a realização de parte deste estudo na Estação Experimental do IPA (Empresa Pernambucana de Pesquisa Agropecuária) de Arcoverde-PE.

\section{Referências bibliográficas}

AGUIAR, C.M.L., MARTINS, C.F. \& MOURA, A.C. 1995. Recursos florais utilizados por abelhas (Hymnoptera, Apoidea) em área de Caatinga (São João do Cariri, Paraíba). Revista Nordestina de Biologia 10:101-117.

ARMBRUSTER, W.S. \& MCCORMICK, K.D. 1990. Diel foraging patterns of male Euglossine bees: Ecological causes and evolutionary response by plants. Biotropica 22:160-171.

ARMBRUSTER, W.S. \& STEINER, K.E. 1992. Pollination ecology of four Dalechampia species (Euphorbiaceae) in Northern Natal, South Africa. American Journal of Botany 79:306-313.

ARMBRUSTER, W.S. \& WEBSTER, G.L. 1979. Pollination of two species of Dalechampia (Euphorbiaceae) in Mexico by Euglossine bees. Biotropica 11:278-283.

ARMBRUSTER, W.S., HERZIG, A.L. \& CLAUSEN, T.P. 1992. Pollination of two sympatric species of Dalechampia (Euphorbiaceae) in Suriname by male Euglossine bees. American Journal of Botany 79:1374-1381.

BAKER, H.G. 1975. Sugar concentrations in nectars from hummingbird flowers. Biotropica 7:37-41.

BAKER, H.G. \& BAKER, I. 1983. Floral nectar sugar constituents in relation to pollination type. In Handbook of experimental pollination biology (C.E. Jones \& R.J. Little, eds.). Van Nostrand Reinhold, New York, p.117-141. 
BAWA, K.S. \& BEACH, J.H. 1981. Evolution of sexual systems in flowering plants. Annals of the Missouri Botanical Garden 68:254-274.

BERTIN, R.I. \& NEWMAN, C.M. 1993. Dichogamy in Angiosperms. Botanical Review 59:112-152.

CAMARGO, J.M.F., GOTTSBERGER, G. \& SILBERBAUERGOTTSBERGER, I. 1984. On the phenology and flowers visiting behavior of Oxaea flavescens (Klug) (Oxalinae, Andrenidae, Hymenoptera) in São Paulo, Brazil. Beitrage zur Biologie der Pflanzen 59:159-179.

CHITTKA, L. \& WASER, M.W. 1997. Why red flowers are not invisible to bees. Israel Journal of Plant Science 45:169-183.

CRONQUIST, A. 1981. An integrated system of classification of flowering plants. Houghyon Mifflin, Boston.

CRUDEN, R.W. 1977. Pollen-ovule ratios: a conservative indicator of breeding systems in flowering plants. Evolution 31:32-46.

DAFNI, A. 1992. Pollination Ecology. A practical approach. Oxford University Press, Oxford.

DEHGAN, B. \& WEBSTER, G.L. 1979. Morphology and infrageneric relationships of the genus Jatropha (Euphorbiaceae). University of California Press, Berkeley.

DOMINGUEZ, C.A. \& BULLOCK, S.H. 1989. La reproducción de Croton suberosus (Euphorbiaceae) en luz y sombra. Revista de Biología Tropical 37:1-10.

ENDRESS, P.K. 1994. Diversity and evolutionary biology of tropical flowers. Cambridge University Press, Cambridge.

EPILA-OTARA, J.S. 1993. Foraging behavior of honeybees (Hymenoptera: Apidae) on Jatropha integerrima (Euphorbiaceae) in Upolu, Western Samoa. Micronesica 26:83-94.

FAEGRI, K. \& PIJL, L. VAN DER. 1979. The principles of pollination ecology. Pergamon Press, London.

FIDEM. 2000. Programa Governo nos Municípios. Região de desenvolvimento Agreste Meridional. Companhia Editora de Pernambuco, Recife.

GALLINDO, F. 1985. O gênero Jatropha L. para Pernambuco. Dissertação de mestrado, Universidade Federal Rural de Pernambuco, Recife.

HESSE, M. 1981. Pollenkit and viscin threads: their role in cementing pollen grains. Grana 20:145-152.

LLOYD, D.G. \& WEBB, C.J. 1986. The avoidance of interference between the presentation of pollen and stigmas in angiosperms. I. Dichogamy. New Zealand Journal of Botany 24:135-162.

LOPES, A.V. \& MACHADO, I.C. 1998. Floral biology and reproductive ecology of Clusia nemorosa (Clusiaceae) in northeastern Brazil. Plant Systematics and Evolution 213:71-91.

MACHADO, I.C. \& LOPES, A.V. 2000. Souroubea guianensis Aubl.: quest for its legitimate pollinator and the first record of tapetal oil in the Marcgraviaceae. Annals of Botany 85:705-711.
MACHADO, I.C.S. \& SAZIMA, M. 1995. Biologia da polinização e pilhagem por beija-flores em Ruelia asperula Lindau (Acanthaceae) na Caatinga, Nordeste brasileiro. Revista Brasileira de Botânica 18:27-33.

MACHADO, I.C.S., BARROS, L.M. \& SAMPAIO, E.V.S.B. 1997. Phenology of Caatinga species at Serra Talhada, PE, northeastern Brasil. Biotropica 29:57-68.

MORELLATO, L.P.C., LEITÃOFILHO, H.F., RODRIGUES, R.R. \& JOLY, C.A. 1990. Estratégias fenológicas de espécies arbóreas em florestas de altitude na Serra do Japi, Jundiaí, São Paulo. Revista Brasileira de Biologia 50:149-162.

NEWSTROM, L.E., FRANKIE, G.W. \& BAKER, H.G. 1994. A new classification for plant phenology based on flowering patterns in Lowland Tropical Rain Forest trees at La Selva, Costa Rica. Biotropica 26:141-159.

ORMOND, W.T., PINHEIRO, M.C.B. \& CASTELLS, A.R.C. 1984. Contribuição ao estudo da reprodução e biologia floral de Jatropha gossypifolia L. (Euphorbiaceae). Revista Brasileira de Biologia 44:159-167.

OLIVEIRA, G.M. 1998. Disponibilidade de recursos florais para beija-flores no Cerrado de Uberlândia/MG. Dissertação de mestrado, Universidade de Brasília, Brasília.

PASSOS, L. 1995. A polinização pelo vento. In Ecologia e preservação de uma floresta tropical urbana: Reserva de Santa Genebra (H.F. Leitão Filho \& L.P.C. Morellato, orgs.). Editora da Unicamp, Campinas, p.54-56.

PERCIVAL, M. 1965. Floral Biology. Pergamon Press, Oxford.

PRIMACK, R.B. 1985. Longevity of individual flowers. Annual Review of Ecology and Systematics 16:15-37.

PROCTOR, M., YEO, P. \& LACK. A. 1996. The natural history of pollination. Harper-Colins, London.

RADFORD, A.E., DICKINSON, W.C., MASSEY, J.R. \& BELL, C.R. 1974. Vascular plant systematics. Harper \& Row, New York.

REDDI, E.U.B. \& REDDI, C.S. 1983. Pollination Ecology of Jatropha gossypifolia (Euphorbiaceae). Proceedings of the Indian Academy of Sciences - Plant Sciences 92:215-231.

REDDI, E.U.B. \& REDDI, C.S. 1985. Wind and insect pollination in monoecious and dioecious species of Euphorbiaceae. Proceedings of the Indian Academy of Sciences - Plant Sciences 51:468-482.

SAMPAIO, E.V.S.B. 1995. Overview of the Brazilian caatinga. In Seasonally dry tropical forest (S.H. Bullock, H.A. Mooney \& E. Medina, eds.). Cambridge University Press, Cambridge, p.35-63.

SANTOS, M.J.L. \& MACHADO, I.C. 1998. Biologia floral e heterostilia em Vismia guianensis (Aubl.) Choisy (Clusiaceae). Acta Botanica Brasilica 12 (suplemento):451-464.

SAZIMA, M., SAZIMA, I. \& CARVALHO-OKANO, R.M. 1985. Biologia floral de Dalechampia stipulacea (Euphorbiaceae) e sua polinização por Euglossa melanotricha (Apidae). Revista Brasileira de Biologia 45:85-93. 
TEJADA, C.A.D.P. \& BULLOCK, S.H. 1988. Seed fecundity of monoecious and female plants of a Croton species (Euphorbiaceae). The Southwestern Naturalist 33:233-234.
WEBSTER, G.L. 1994. Euphorbiaceae. Annals of the Missouri Botanical Garden 81:1-144.

WILLSON, M.F. \& ÅGREN, I. 1989. Differential floral rewards and pollination by deceit in unisexual flowers. Oikos 55:23-29. 